\title{
Sexual orientation and spatial ability in men and women
}

\author{
BRIAN A. GLADUE and WILLIAM W. BEATTY \\ North Dakota State University, Fargo, North Dakota \\ JAN LARSON \\ Northwest Human Service Center, Williston, North Dakota \\ and \\ R. DENNIS STATON \\ Veterans Administration Medical Center, Fargo, North Dakota
}

\begin{abstract}
The performance by groups of male and female homosexuals and heterosexuals on three tests of spatial ability was studied. The groups were closely matched in terms of age, education, and vocational interests. Male homosexuals performed more poorly than male heterosexuals on a version of the water jar test and on the Mental Rotation Test, but the groups did not differ on measures of geographical knowledge or verbal ability. Female homosexuals and heterosexuals at. tained similar scores on all cognitive variables except the water jar test; on this task, the homosexual females performed more poorly than the heterosexual females. The influence of sexual orientation on visuospatial tasks could not be explained on the basis of self-reports of masculinity and femininity, or on the basis of experience with activities thought to foster the development of spatial skills. Such factors, however, acting in concert with biological influences that are not yet known, may have parallel effects on the development of sexual orientation and visuospatial ability.
\end{abstract}

Although controversial, gender differences in certain cognitive abilities have been widely reported. In general, adult males are reported to have superior visuospatial abilities, whereas women outperform men on certain verbal tasks (for reviews, see Halpern, 1986; Maccoby \& Jacklin, 1974). The origin of these differences in cognitive function is unknown. Two principal explanations, each with many variants, have been offered: psychosocial and biological. On the one hand, cognitive differences between men and women are viewed as the end product of different experiences and expectations produced by socialization. Included in this viewpoint is the idea that masculine or feminine self-concept and experience with activities might influence the development of spatial ability (Newcombe, Bandura, \& Taylor, 1983). Using meta-analysis,

This research was supported with funds provided by the National Science Foundation Experimental Program to Stimulate Competitive Research (NSF-EPSCoR), the ASEND Project (Achieving Science Excellence in North Dakota), the Neuropsychiatric Institute (Fargo, ND), and the NSF Research Experiences for Undergraduates program. We are very grateful to the Prairie Gay and Lesbian Community, its members, friends, and officers for their cooperation and support of this research program. We wish to thank the following research assistants and staff members for their contributions to all aspects of the project such as subject interviewing, data gathering, coding, and entry (in alphabetical order): Joel Bakken, Michael Boechler, H. Jean Delaney, Mark Ehrmantraut, Donna Johnson, Jane Melroe, Brenda Milland, and Jacki Schempr. Correspondence may be addressed to Brian A. Gladue, Department of Psychology, 115 Minard Hall, North Dakota State University, Fargo, ND 58105.
Signorella and Jamison (1986) found that higher masculine and lower feminine self-concept scores were both associated with better performance on spatial tasks.

On the other hand, biological factors (i.e., differences in the development of relevant brain circuits) may be seen as the critical determinants of gender differences in cognition (Halpern, 1986; Kimura \& Harshman, 1984). Similar psychosocial and biological arguments have been advanced to account for differences in psychosexual development; that is, differences in sexual orientation (i.e., erotic partner preference) among men are considered to result from either biological influences on brain organization and subsequent sexual behavior (Gladue, 1988; Meyer-Bahlburg, 1984; Money, 1987) or critical psychosocial childhood or early adolescent events (Green, 1987; Storms, 1980).

Recently, Sanders and Ross-Field (1987) have suggested that levels of gonadal hormones present during a critical perinatal period may influence the development of both sexual orientation and cognitive ability by influencing brain development. This hypothesis has some empirical support. Finegan, Zucker, Bradley, and Doering (1982) reported a study in which boys with gender identity disorder of childhood (GIDC), a condition reportedly having continuity with homosexual erotic preference in adulthood (Green, 1987; Whitam \& Mathy, 1986), were compared with their nonaffected brothers and with control patients without GIDC on measures of spatial and verbal ability. Although no differences were found on measures 
of full-scale IQ and verbal abilitiy, the GIDC boys performed more poorly on the spatial subtest (block design) than on the vocabulary subtest, and underperformed on the block design subtest relative to psychiatric controls. Wilmott and Brierley (1984) reported that scores obtained by homosexual men on the Wechsler Adult Intelligence Scale (WAIS) performance IQ measure (which reflects spatial ability in part) were lower than those of heterosexual men, and comparable to those of heterosexual women. The homosexual men scored significantly higher than the heterosexual men on the WAIS verbal IQ measure. Finally, Sanders and Ross-Field (1986b) reported that homosexual men underperformed heterosexual men on two measures of spatial ability, the Piagetian water-level task and the Vincent Mechanical Diagrams Tests. In that study as well, the performance of the homosexual men was comparable to that shown by a group of heterosexual women. That biological factors might underlie these cognitive differences between men of differing psychosexual histories is suggested by the work of Hier and Crowley (1982), who reported poor spatial performance by men with a congenital androgen deficiency (idiopathic hypogonadotropic hypogonadism, IHH). In these men, severely deficient developmental and adult hormonal levels and prepubertal genital morphology result from an isolated deficiency of gonadotropin releasing hormones. Hier and Crowley found that such men continued to exhibit poor spatial ability even when given androgen replacement therapy. Although the psychosexual development and sexual orientation of those subjects was not described and continues to be a poorly described aspect of research on IHH males (Heino Meyer-Bahlburg, personal communication, October 1989), the report was nonetheless interesting, since it indicated that spatial (but not verbal) cognitive deficits might be related to androgenorganized brain tissues.

Linn and Petersen (1985) have described three distinct spatial ability factors: spatial perception, mental rotation, and spatial visualization. Using meta-analysis, those authors demonstrated that adult men outperform women on tests of spatial perception and mental rotation, but not on spatial visualization tasks. Therefore, most previous studies of spatial ability in gender-identity-disturbed males (Finegan et al., 1982) or homosexual men (Wilmott \& Brierley, 1984) appear to lack important specificity regarding types of spatial ability.

In the present study, we examined spatial perception, mental rotation ability, and ability to perform a mapreading spatial task in groups of heterosexual and homosexual men and women. Spatial perception was measured using a variant of the water jar test, on which male undergraduates outperformed females in a previous study (Beatty \& Duncan, in press). The Mental Rotations Test, developed by Vandenberg and Kuse (1978), provided a second independent measure of spatial ability. This test has consistently been shown to be sensitive to gender (Beatty \& Duncan, in press; Linn \& Petersen, 1985). A third spatial measure, the Fargo Map Test
(Beatty, 1988), was also administered. On this test, males consistently outperform females in samples drawn from various geographic regions and ranging in age from 18 to 70 years and older (Beatty, 1989; Beatty \& Troester, 1987).

Masculinity, femininity, and androgyny were measured with the Bem (1974) scale. Experience with activities that might be related to spatial skill was assessed with the Everyday Spatial Activities Test (ESAT; Lunneborg \& Lunneborg, 1986b). On the ESAT, male college students report greater familiarity with the use of tools and greater exposure to science and mechanical drawing (Beatty \& Duncan, in press); Lunneborg \& Lunneborg, 1986b) than do females. Furthermore, ESAT scores are moderately correlated with performance on standarized tests of spatial ability (Beatty \& Duncan, in press; Lunneborg \& Lunneborg, 1986a).

To our knowledge, the present study is the first to compare spatial performance of heterosexual and homosexual women. Since women exposed prenatally to "masculinizing" hormones are more likely to report lesbian or bisexual orientation in adulthood (Ehrhardt et al., 1985; Money, 1987) and a somewhat masculine pattern of cerebral lateralization (Hines \& Shipley, 1984), we expected that homosexual women would outperform heterosexual women on spatial tasks. More generally, however, we explored the possibility that there might be a difference in spatial ability between heterosexual and homosexual women comparable to the apparent difference in spatial ability that is reported to exist between heterosexual and homosexual men.

\section{METHOD}

\section{Subjects}

Subjects were recruited to participate in a broad research investigation of the psychobiology of gender and sexual orientation. In response to newspaper and poster advertisements, as well as referrals from friends and previous volunteers, interested persons contacted the laboratory for further information and to arrange for participation. These persons were then scheduled to visit the laboratory, where they were informed of the purpose of the study and gave informed consent. Shortly thereafter, a person-to-person interview was conducted by a trained experimenter who inquired about past and current sexual behaviors and attitudes. The method employed utilized the semistructured interview instrument and technique of Meyer-Bahlburg and Ehrhardt (Sexual Experiences, Behaviors and Attitudes Survey-Adult, 1983 version) and lasted approximately $1 \mathrm{~h}$ for each subject. In addition, the subjects completed several questonnaires regarding psychosexual milestones, sexual history, attitudes, and behavior, as well as demographic information.

As a result of information obtained in the questionnaires and interview, the subjects were categorized regarding their lifelong sexual orientation using the so-called Kinsey rating scale, in which Kinsey 0 represents persons exclusively heterosexual in fantasy and behavior, and Kinsey 6 indicates persons exclusively homosexual in fantasy and behavior (Kinsey, Pomeroy, \& Martin, 1948; Kinsey, Pomeroy, Martin, \& Gebhard, 1953). Only data from persons with either exclusve lifelong (since puberty) heterosexual or exclusive lifelong homosexual histories are reported here. ${ }^{1}$ Finally, attempts were made to match groups of subjects within gender for age, educational level, and current and desired occupation (Table 1). 
Table 1

Background Characteristics of Subject Groups

\begin{tabular}{|c|c|c|c|c|}
\hline & \multicolumn{2}{|c|}{ Males } & \multicolumn{2}{|c|}{ Females } \\
\hline & $\mathrm{HT}$ & HS & $\mathrm{HT}$ & HS \\
\hline$n$ & 16 & 16 & 15 & 15 \\
\hline Age (years) & $28.1(1.2)^{*}$ & $27.3(1.8)$ & $27.5(1.1)$ & $26.7(1.5)$ \\
\hline Range: & $22-36$ & $22-37$ & $21-32$ & $21-32$ \\
\hline Education (years) & $14.5(0.3)$ & $15.3(0.7)$ & $14.9(0.5)$ & $14.9(0.4)$ \\
\hline Range: & $12-19$ & $12-19$ & $12-18$ & $12-19$ \\
\hline \multicolumn{5}{|c|}{ Current Occupation } \\
\hline Prof/Manag/Tech & 2 & 3 & 2 & 2 \\
\hline Clerical/Sales & 0 & 0 & 3 & 2 \\
\hline Service/Blue Collar & 3 & 2 & 2 & 3 \\
\hline \multicolumn{5}{|l|}{ Student } \\
\hline Math-Sci-Engineer & 6 & 6 & 4 & 4 \\
\hline Social Sci-Hum & 5 & 5 & 4 & 4 \\
\hline \multicolumn{5}{|c|}{ Desired Occupation } \\
\hline Prof/Manag/Tech & 15 & 14 & 13 & 14 \\
\hline Clerical/Sales & 0 & 0 & 0 & 0 \\
\hline Service/Blue Collar & 1 & 2 & 2 & 1 \\
\hline Student & 0 & 0 & 0 & 0 \\
\hline
\end{tabular}

Note-Occupation values represent actual number of subjects. HT $=$ heterosexuals; HS $=$ homosexuals. *Values represent the mean and, in parentheses, the standard error of the mean.

The subjects indicated their current occupation as well as the occupation they desired or were training toward. Occupations were grouped according to the method of Purifoy and Koopmans (1979), employing U.S. Employment Service categories: professional, managerial, and technical (Prof/Manag/Tech); clerical and sales; service (includes restaurant and hotel) and manual laborers of any craft (Service/Blue Collar); and student. Students were grouped according to major area of study: Math-Sci-Engineer for those indicating a major in the natural sciences, including mathematics and architecture, and Social Sci-Hum for those declaring a major in social sciences, humanities, or the performing arts. Female groups were additionally matched for recent menstrual history (average length of menstrual cycle in the past three cycles). All women in this report participated during the early follicular phase of their menstrual cycle. A total of 62 subjects completed all phases of this study: 16 heterosexual men (MHT), 16 homosexual men (MHS), 15 heterosexual women (FHT), and 15 homosexual women (FHS).

\section{Materials and Procedure}

The subjects completed a set of cognitive questionnaires, tests, and measures during their visit to the laboratory. Testing occurred in groups of 2-5 persons over a $1-\mathrm{h}$ period on a single afternoon. All subjects received cash remuneration as compensation for their time and participation. The protocol and consent form were approved and certified by an institutional review board.

Water jar test. A paper-and-pencil version of the water jar problem was used. The subjects were first shown an outline drawing of a jar capped with a cork. The jar was resting cork-side up on a horizontal line that was identified as a "table." The subjects were told that the jar was half full of water as indicated by the horizontal line (the "water line") parallel to the table. They were told that on the following pages the jar would be shown in various orientations and that they were to draw the water line as it should appear using a pencil and the straight-edge provided. The jar was depicted in eight different orientations $(1,2,4,5,7,8,10$, and 11 o'clock) arranged in a random sequence. Each item was scored as correct (subject's line was within $4^{\circ}$ of horizontal) or incorrect, as well as the average number of degrees deviation from horizontal. The height of the water line was not considered in the scoring.
Mental Rotation Test. The subjects were allowed a total of $6 \mathrm{~min}$ to complete the 20 items on the Mental Rotations Test (Vandenberg \& Kuse, 1978). They were instructed that for each item there were two correct and two incorrect answers. On a particular item, the subjects received 2 points if they marked both correct choices and 1 point if they marked only one correct choice. All other responses received a score of 0 for the item. Maximum possible was 40 points.

Everyday Spatial Activities Test (ESAT). There was no time limit for the subjects to complete the 20 items on the ESAT (Lunneborg \& Lunneborg, 1986b). Each item was scored on a 6-point scale $(0=$ no familiarity with the activity, $5=$ very good familiarity), and separate scores were derived for the Hand Tools, Science Courses, Arranging Objects, and Mechanical Drawing subscales by totaling the scores on the relevant items. In addition, the total score was derived by summing the scores on the four subscales.

Bem Scale of Masculinity-Femininity-Androgyny (Bem). The subjects completed a 60 -item scale asking how well each of the masculine, feminine, and neutral personality characteristics describes her/himself (Bem, 1974). Items were scored on a 7-point scale (0-6) and are reported here as three separate scale scores: masculinity, femininity, and the difference between the two (androgyny).

Tests of verbal ability. As a check on the capacity of the subjects for verbal comprehension and expression, two gross measures of verbal ability were employed in this study: verbal fluency and the Shipley-Hartford (Pollack, 1942) vocabulary test. In the verbal fluency task, a modified version of the controlled oral wordassociation test (Borkowski, Benton, \& Spreen, 1967) was administered. Each subject was tested individually in privacy and asked to say, in a 60 -sec period, as many English words as possible beginning with the letter $F$. The procedure was then repeated for the letter $\mathrm{A}$, and again for $\mathrm{S}$. Responses were tape-recorded, then transcribed. On the Shipley-Hartford test, the subjects were given a list of 40 words and were instructed to select the correct synonym from a group of 4 words alongside each of the 40 target words. Maximum possible score on this task was 40 .

Tests of geographical knowledge. The revised version of the Fargo Map Test (Beatty, 1988) requires subjects to locate 10 gross features of U.S. geography (e.g., Atlantic Ocean) and 30 U.S. cities 
on an outline map of the U.S. As a verbal measure of geographical knowledge, the subjects also indicated in which state each of the 30 cities is located (termed city/state). Furthermore, as a measure of knowledge of geography of the local region, the subjects were asked to locate 18 cities on an outline map of the tristate region (ND, SD, MN).

Statistical analyses. For measures of cognitive ability and the Bem scale, data were analyzed using a 2 (gender) $\times 2$ (sexual orientation) ANOVA. Subsequent post hoc tests were conducted using two-tailed $t$ tests. Although some argument could be made that onetailed $t$ tests would be appropriate for hypotheses in which, for example, heterosexual men might be expected to outperform homosexual men on certain cognitive skills, we preferred a more conservative statistical approach, especially in the absence of large sample sizes.

\section{RESULTS}

\section{Demographics}

There were no age differences by gender, nor were there any significant age differences between heterosexuals and homosexuals within gender (Table 1). Similarly, no differences between or within gender were obtained in years of education, present or desired occupational categories, or students' college majors.

\section{Spatial Perception}

There were no significant differences among groups when performance on the water jar test was evaluated by simply counting the number of problems answered correctly. However, when the average deviation from horizontal was employed as the dependent variable, homosexuals (both men and women) performed more poorly than heterosexuals $[F(1,58)=5.87, p<.02]$, as shown in Figure 1. Neither the main effect of gender nor the gender $\times$ sexual orientation interaction was statistically significant (all $F_{\mathrm{S}}<1.0$ ). Thus, on this measure, after controlling for age, education, and occupation, it would appear that differences in sexual orientation (heterosexual vs. homosexual) have a greater effect than do gender (male vs. female) differences.

\section{Mental Rotation}

There were significant differences by gender and within gender on the Mental Rotations Test. A 2 (gender) $\times 2$ (orientation) ANOVA revealed a significant gender difference $[F(1,58)=8.24, p<.006]$, in which males outperformed females. A marginal effect of sexual orientation was obtained $[F(1,58)=3.54, p<.065]$, and there was a significant interaction between gender and sexual orientation $[F(1,58)=6.42, p<.015]$. Subsequent comparisons revealed that homosexual men scored significantly lower than heterosexual men $[t(30)=2.97$, $p<.01$ ], whereas the scores of homosexual women did not differ from those of the heterosexual women $[t(28)$ $<$ 1] (Figure 2).

The impact of occupation or major area of study on the subjects' scores on the Mental Rotations and water jar tests was evaluated with separate ANOVAs. There was no main effect of occupation on either task, nor were there any significant interactions with gender or sexual orientation (all $F \mathrm{~s}<1$ ).

\section{Fargo Map Test}

As shown in Table 2, males had higher scores than females on most measures of geographical knowledge. Males were significantly more knowledgeable than females on U.S. cities $[F(1,58)=11.92, p<.001]$, cities/states $[F(1,58)=3.99, p<.05]$, and tri-state region geography $[F(1,58)=5.77, p<.02]$. And although there was no gender difference on knowledge of gross geographical features of the U.S., the nonsignificant trend favored males. Thus, on most measures of geographical knowledge, a gender difference existed, confirming the earlier reports

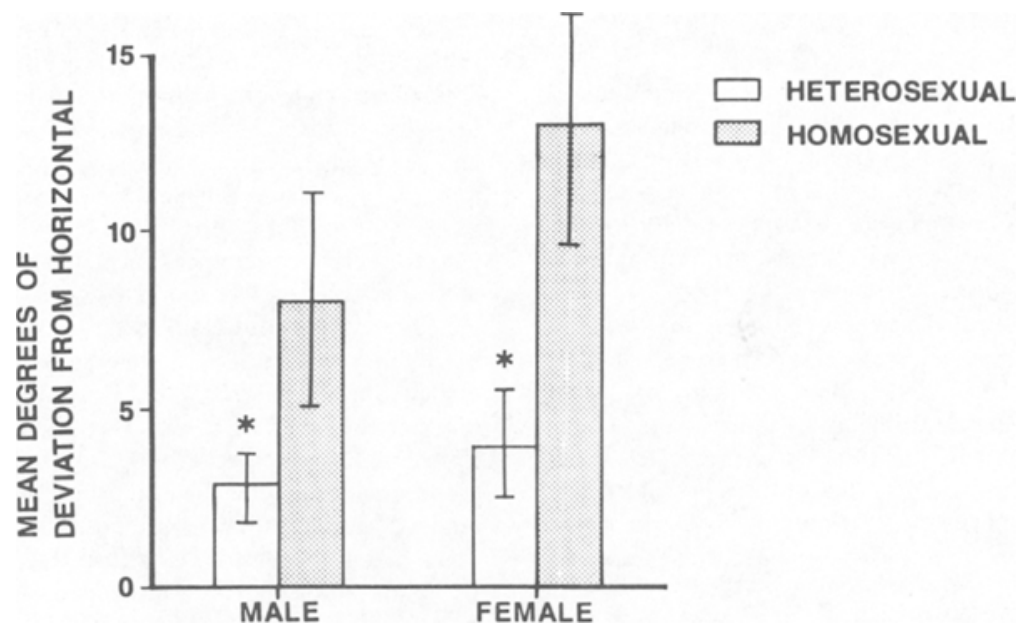

Figure 1. Water jar test scores in heterosexual and homosexual men and women depicted as degrees of deviation from the horizontal plane averaged across all eight jar depictions. Vertical bars represent $S E M s$. * $p<.05$. 


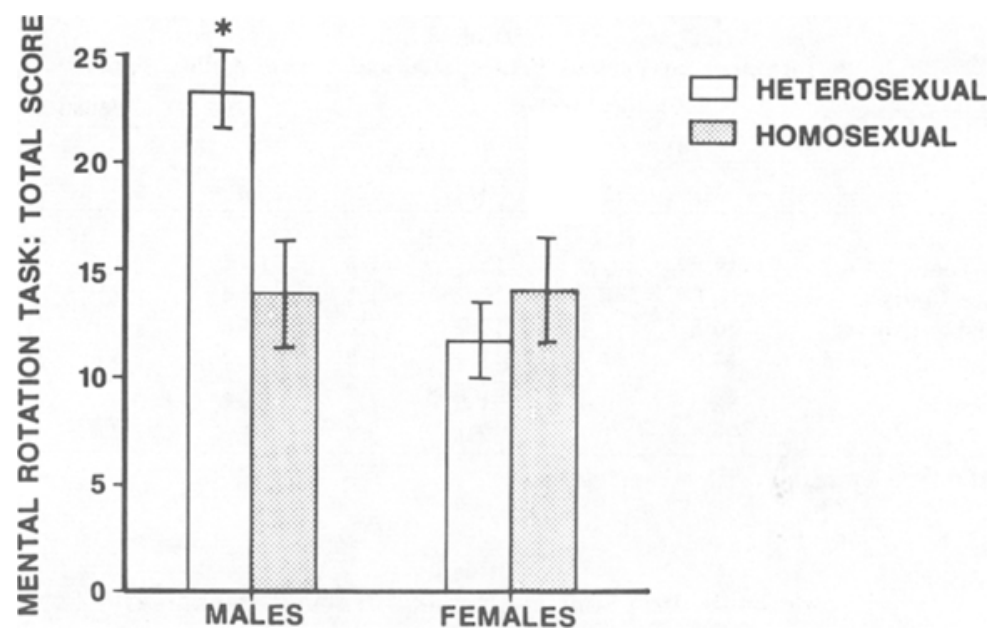

Figure 2. Mean Mental Rotation Task scores in heterosexual and homosexual men and women. Vertical bars represent SEMs. ${ }^{*} p<.05$.

by Beatty and Troester (1987) and Beatty (1989), in which men showed greater geographical knowledge than women. Note that this gender difference was found in groups closely matched for occupation and education. There were no significant differences by sexual orientation, nor were there any significant interactions of gender and sexual orientation on any aspect of the map test.

\section{ESAT}

Self-report of everyday spatial ability (ESAT) did not significantly differ by gender or by sexual orientation on any of the four subscales: Hand Tools, Science Courses, Arranging Objects, and Mechanical Drawing (Table 3). There were two marginally significant gender trends: females overall tended to score higher on Arranging Objects $[F(1,58)=3.73, p<.059]$, and males had slightly higher scores for Mechanical Drawing $[F(1,58)=3.61$, $p<.062]$. There were no within-gender differences (HT vs. HS) on any subscale (all $t \mathrm{~s}<2$, all $p s>.05$, twotailed test).

\section{Verbal Ability}

There were no significant main effects or interactions on either the measure of verbal comprehension or verbal expression.

\section{Gender Role (Bem Scale)}

Men and women in this study differed on a scale of masculinity, but not on a measure of femininity (Table 4). As measured by the Bem scale, males scored higher on masculinity $[F(1,58)=23.84, p<.001]$, with a significant gender $X$ orientation interaction $[F(1,58)=12.61$, $p<.001]$. Post hoc analysis revealed that HT men scored higher on masculinity than did HS men $[t(30)=3.64$, $p<.001]$, although both groups of men were similar on a measure of femininity $[t(30)=1.00, p<.3]$. Heterosexual women were equally masculine and feminine compared with the homosexual women (all $F \mathrm{~s}<1$ ).

\section{DISCUSSION}

The present comparison of visuospatial performance among heterosexual and homosexual men and women reveals a significant relationship between sexual orientation and spatial ability, although the relationship is subtle and appears more prominent in men than in women. Homosexual men performed more poorly than heterosexual men on our version of both the water jar test and the Mental Rotations Test, but the two groups did not differ in geographical knowledge or on either test of verbal ability. Hence, the cognitive differences between homosexual and

Table 2

Performance on Measures of Geographical Knowledge (Fargo Map Test)

\begin{tabular}{|c|c|c|c|c|c|c|c|c|}
\hline & \multicolumn{4}{|c|}{ Males } & \multicolumn{4}{|c|}{ Females } \\
\hline & \multicolumn{2}{|c|}{ HT } & \multicolumn{2}{|c|}{ HS } & \multicolumn{2}{|c|}{ HT } & \multicolumn{2}{|c|}{ HS } \\
\hline & $M$ & $S D$ & $M$ & $S D$ & $M$ & $S D$ & $M$ & $S D$ \\
\hline U.S. gross score (10) & 9.1 & 0.7 & 9.2 & 0.5 & 9.2 & 0.2 & 8.4 & 0.6 \\
\hline U.S. Cities (30) & 18.6 & 0.8 & 18.1 & 1.9 & 14.5 & 1.4 & 12.5 & 1.0 \\
\hline Cities/States (30) & 29.3 & 0.2 & 28.3 & 0.9 & 28.5 & 0.4 & 26.1 & 1.4 \\
\hline Tri-State Region (18) & 13.1 & 0.8 & 12.4 & 1.0 & 11.4 & 0.8 & 9.0 & 1.6 \\
\hline
\end{tabular}

Note-HT $=$ heterosexuals, HS $=$ homosexuals. 
Table 3

Performance on Various Visuospatial and Verbal Ability Tasks

\begin{tabular}{|c|c|c|c|c|c|c|c|c|}
\hline & \multicolumn{4}{|c|}{ Males } & \multicolumn{4}{|c|}{ Females } \\
\hline & \multicolumn{2}{|c|}{ HT } & \multicolumn{2}{|c|}{ HS } & \multicolumn{2}{|c|}{$\mathrm{HT}$} & \multicolumn{2}{|c|}{ HS } \\
\hline & $M$ & $S D$ & $M$ & $S D$ & $M$ & $S D$ & $M$ & $S D$ \\
\hline \multicolumn{9}{|l|}{ ESAT } \\
\hline Hand Tools & 19.2 & 0.9 & 15.5 & 1.8 & 16.4 & 1.1 & 14.8 & 1.3 \\
\hline Science Courses & 16.7 & 1.2 & 16.2 & 1.1 & 16.4 & 1.2 & 14.1 & 0.9 \\
\hline Arranging Objects & 16.8 & 1.4 & 17.7 & 1.2 & 19.6 & 1.0 & 19.4 & 0.8 \\
\hline Mechanical Drawing & 13.8 & 1.7 & 12.9 & 1.8 & 11.7 & 1.5 & 10.8 & 1.2 \\
\hline Vocabulary & 32.5 & 0.9 & 31.5 & 1.5 & 33.0 & 0.9 & 32.2 & 1.3 \\
\hline Verbal Fluency & 39.2 & 1.7 & 37.1 & 3.4 & 39.0 & 2.4 & 39.1 & 4.2 \\
\hline
\end{tabular}

Note-HT $=$ heterosexuals, HS $=$ homosexuals.

Table 4

Scores on the Bem Scale of Masculinity-Femininity-Androgyny

\begin{tabular}{|c|c|c|c|c|c|c|c|c|}
\hline & \multicolumn{4}{|c|}{ Males } & \multicolumn{4}{|c|}{ Females } \\
\hline & \multicolumn{2}{|c|}{ HT } & \multicolumn{2}{|c|}{ HS } & \multicolumn{2}{|c|}{ HT } & \multicolumn{2}{|c|}{ HS } \\
\hline & $M$ & $S D$ & $M$ & $S D$ & $M$ & $S D$ & $M$ & $S D$ \\
\hline Masculinity & $5.68^{*}$ & 0.11 & 4.76 & 0.16 & 4.32 & 0.20 & 4.58 & 0.12 \\
\hline Femininity & 4.62 & 0.15 & 4.82 & 0.14 & 4.39 & 0.20 & 4.69 & 0.12 \\
\hline Androgyny & $1.06^{*}$ & 0.20 & -0.05 & 0.13 & -0.07 & 0.19 & -0.11 & 0.17 \\
\hline
\end{tabular}

Note $-\mathrm{HT}=$ heterosexuals, $\mathrm{HS}=$ homosexuals. ${ }^{*} p<.05$, comparing HT versus HS males.

heterosexual men were specific to the two measures of visuospatial ability. In this regard, the present findings confirm the earlier results of Sanders and Ross-Field (1986a, 1986b). Although we found no differences in gross measurements of verbal ability, our measures, which were intended to preclude participation of persons who had a reading disability, gross verbal dysfunction, or overt neuropsychological pathology, may not have been sufficiently sensitive. Wilmott and Brierly (1984), utilizing a more rigorous assessment (WAIS subtests), reported higher verbal ability scores in homosexual than in heterosexual men.

The poorer visuospatial performance by our homosexual male sample cannot be attributed to age, education, occupation, or lack of exposure to activities that might foster the development of spatial skills (as measured by the ESAT), since the two groups were closely matched on these variables. The homosexual men did perceive themselves to be less masculine than the heterosexual men as measured by the Bem (1974) scale. Since lower scores on scales of masculinity are associated with poorer performance on spatial tasks (Signorella \& Jamison, 1986), this difference may be important even though no significant correlations between self-reported masculine (or feminine) characteristics and any measure of spatial ability were observed in the present study (all $r \mathrm{~s}<0.15$, ps $>.1$. .

For women, a different situation was found: although homosexual women erred more on the water jar test, the performance of these women on other tasks of spatial ability did not significantly differ from those of their heterosexual female peers. This is especially noteworthy since, to the best of our knowledge, this is the first report of spatial ability assessment in closely matched homosexual and heterosexual women. Furthermore, and contrary to an expectation that homosexual women would show "male-like" performances, the scores of these women were either no different or poorer than those of their heterosexual peers. This was also evident on the self-report ESAT and geographical knowledge measures, where homosexual women indicated less spatial ability, although the differences were not statistically significant. Finally, homosexual and heterosexual women were virtually identical on self-report measures of masculinity-femininity. Thus, on balance, homosexual women are either no different from their heterosexual counterparts, or are even more "female-like" in their spatial abilities. The possibility that homosexual women might have spatial abilities comparable to those of men is not even slightly supported by these findings. It may very well be inappropriate to attempt to understand female homosexuality as a "male-like" counterpart of male homosexuality: quite possibly, in terms of cognitive ability (the present study) and aggressive behavioral characteristics (Gladue, unpublished observations), lesbian women may represent the more "female" region of such masculine-feminine continua.

Interpretation of the results of the water jar test is complicated by our failure to observe a significant sex difference among heterosexuals. Heterosexual females averaged 6.0 (out of 8) problems correct, compared to 6.4 for heterosexual males. In an earlier study in which subjects were not identified by sexual orientation, Beatty and Duncan (in press) reported that females averaged 4.2 correct, versus 6.1 for males. Thus, the discrepant results arise largely as a consequence of the much better performance by females in the present study. Since exactly the same 
version of the water jar test was used in both studies, it cannot be argued that the version of the test we used is insensitive to sex differences.

Several procedural differences, alone or in combination, may account for the discrepant water jar test results. Beatty and Duncan (in press) tested 59 male and 61 female undergraduates. Their study therefore had more statistical power than the present study. On average, the subjects in the Beatty and Duncan study were younger (by about 5 years) and had less formal education (by about 1 year) than the subjects in the present study. Furthermore, Beatty and Duncan made no attempt to equate their groups in terms of occupation and vocational interests, whereas this factor was controlled in the present study. Vocational interests may be important, since performance on tests of horizontality (such as the water jar test) by female college students is strongly influenced by their academic major (Kalichman, 1986).

The differences between heterosexual males and females on the ESAT scales in the present study were much smaller in magnitude than the gender differences on the same measures observed by Beatty and Duncan (in press). Those authors found that the total score on the ESAT was significantly correlated with performance on the water jar test in both male and female samples, and that the total ESAT score was the best single predictor of performance on this test of several potential predictor variables considered. Hence, it is likely that some aspect of the procedures used to recruit subjects in the present study (matching of vocational interest) resulted in the selection of groups of heterosexual men and women that did not differ in their exposure to "real world" spatial activities or in their performance on the water jar task.

Even if one accepts the notion that everyday spatial experiences, which ordinarily differentiate men and women, contribute to differences that are usually observed on tests of spatial perception (like the water jar task), experience does not explain the gender differences in performance on the Mental Rotations and Fargo Map tests. Since no sexual orientation differences were observed on the ESAT, it is doubtful that experience with spatial activities could account for the poorer performance of homosexuals on the water jar and Mental Rotations tests. Because scores on masculinity or femininity were not significantly correlated with performance on the various spatial tests, it is unlikely that visuospatial ability differences among heterosexual and homosexual men and women can be attributed to self-expectation or adherence to a gendertypical role. We are inclined, therefore, to suggest that some biological factor may significantly contribute to the spatial ability differences described above.

Incorporating biological influences into an explanation of gender or sexual orientation differences in spatial abilities is speculative at this time, owing to a paucity of neurobiological support. Although some evidence exists to support the notion that perinatal and/or pubertal hor- monal factors might influence the development of cognitive processes (Hier \& Crowley, 1982; Hines \& Shipley, 1984; Nyborg, 1984; Reinisch \& Sanders, 1984), a body of convincing corroborative evidence has yet to be established. It therefore seems most prudent to postulate that variations in spatial ability derive from a combination of biological (genetic, neuronal, hormonal) and psychosocial (learning, environmental) influences. To the extent that psyochosocial processes might influence the development of sexual orientation, they may also have an impact upon neuropsychological development (Finegan et al., 1982; Sanders \& Ross-Field, 1987). Nonetheless, our results are more compatible with a biological than with a psychosocial explanation of gender and sexual orientation differences in certain aspects of spatial ability, and they point to the need for further experimental exploration of this possibility.

\section{REFERENCES}

Beatty, W. W. (1988). The Fargo Map Test: A standardized method for assessing remote memory for visuospatial information. Journal of Clinical Psychology, 44, 61-67.

BEATTY, W. W. (1989). Geographical knowledge throughout the lifespan. Bulletin of the Psychonomic Society, 27, 379-381

BeAtTy, W. W. \& DUNCAN, D. (in press). Relationship between performance on the Everyday Spatial Activities Test and on objective measures of spatial behavior in men and women. Bulletin of the Psychonomic Society

Beatty, W. W., Troester, A. I. (1987). Gender differences in geographical knowledge. Sex Roles, 16, 565-590.

BEM, S. L. (1974). The measurement of psychological androgyny. Journal of Consulting \& Clinical Psychology, 42, 155-162.

Borkowski, J., Benton, A., \& SPREen, O. (1967). Word fluency and brain damage. Neuropsychologia, $5,135-140$.

Coleman, E. (1987). Assessment of sexual orientation. Journal of Homosexuality, 14, 9-24.

Ehrhardt, A. A., Meyer-Bahlburg, H. F. L., Rosen, L. R., Feld man, J. F., Veridiano, N. P., Zimmerman, I., \& MCEwen, B. S, (1985). Sexual orientation after prenatal exposure to exogenous estrogen. Archives of Sexual Behavior, 14, 57-78.

Ellis, L., Burke, D., \& AMES, M. A. (1987). Sexual orientation as a continuous variable: A comparison between the sexes. Archives of Sexual Behavior, 16, 523-529.

Finegan, J. K., Zucker, K. J., Bradley, S. J., \& Doering, R. W. (1982). Patterns of intellectual functioning and spatial ability in boys with gender identity disorder. Canadian Journal of Psychiatry, 27, 135-139.

Gladue, B. A. (1988). Hormones in relationship to homosexual/bisexual/heterosexual gender orientation. In J. M. A. Sitsen (Ed.), Handbook of sexology, Vol. 6: The pharmacology and endocrinology of sexual function (pp. 388-409). New York: Elsevier.

GREEN, R. (1987). The "sissy boy syndrome" and the development of homosexuality. New Haven, CT: Yale University Press.

HalPERN, D. F. (1986). Sex differences in cognitive abilities. Hillsdale, NJ: Erlbaum.

HiER, D. B., \& CROWLEY, W. F., JR. (1982). Spatial ability in androgendeficient men. New England Journal of Medicine, 306, 1202-1205.

Hines, M., \& ShIPLeY, C. (1984). Prenatal exposure to diethylstilbestrol (DES) and the development of sexually dimorphic cognitive abilities and cerebral lateralization. Developmental Psychology, 20, 81-94.

Kalichman, S. C. (1986). Horizontality as a function of sex and academic major. Perceptual \& Motor Skills, 63, 903-906.

Kimura, D., \& Harshman, R. A. (1984). Sex differences in brain or- 
ganization for verbal and non-verbal functions. In G. J. DeVries, J. P. C. DeBruin, H. B. M. Uylings, \& M. A. Corner (Eds.), Sex differences in the brain (Progress in Brain Research, Vol. 61, pp. 423-441). New York: Elsevier.

Kinsey, A. C., Pomeroy, W. B., \& Martin, C. E. (1948). Sexual behavior in the human male. Philadelphia: Saunders.

Kinsey, A. C., Pomeroy, W. B., Martin, C. E., \& Gebhard, P. H. (1953). Sexual behavior in the human female. Philadelphia: Saunders.

LinN, M. C., \& PeTersen, A. C. (1985). Emergence and characterization of sex differences in spatial ability: A meta-analysis. Child Development, 56, 1479-1498.

LunNeborg, P. W., Lunneborg, C. E. (1986a, August). Correlates with Everyday Spatial Activities Test scores for the sexes. Paper presented at the Annual Meeting of the American Psychological Association, Washington, DC.

LunNeborg, P. W., LunNeborg, C. E. (1986b). Everyday Spatial Activities Test for studying differential spatial experience and vocational behavior. Journal of Vocational Behavior, 28, 135-141.

MACCOBY, E. E., \& JACKLIN, C. N. (1974). The psychology of sex differences. Stanford, CA: Stanford University Press.

Meyer-Bahlburg, H. F. L. (1984). Psychoendocrine research on sexual orientation: Current status and future options. In G. J. DeVries, J. P. C. DeBruin, H. B. M. Uylings, \& M. A. Corner (Eds.), Sex differences in the brain (Progress in Brain Research, Vol. 61, pp. 375398). New York: Elsevier.

Meyer-Bahlburg, H. F. L., \& Ehrhardt, A. A. (1983). Sexual Behavior Assessment Schedule-Adult (SEBAS). New York: Heino F. L. Meyer-Bahlburg \& Anke A. Ehrhardt.

MONEY, J. (1987). Sin, sickness or status? Homosexual gender identity and psychoneuroendocrinology. American Psychologist, 42, 384-399.

Newcombe, N., Bandura, M. M., \& TAylor, D. G. (1983). Sex differences in spatial ability and spatial activities. Sex Roles, 9, 377-385.

NYBORG, H. (1984). Performance and intelligence in hormonally different groups. In G. J. DeVries, J. P. C. DeBruin, H. B. M. Uylings, \& M. A. Corner (Eds.), Sex differences in the brain (Progress in Brain Research, Vol. 61, pp. 491-508). New York: Elsevier.

Pollack, B. (1942). The validity of the Shipley-Hartford Retreat Test for "deterioration." Psychiatric Quarterly, 16, 119-131.

Purifoy, F. E., \& Koopmans, L. H. (1979). Androstenedione, testosterone, and free testosterone concentration in women of various occupations. Social Biology, 26, 179-188.

ReINISCH, J. M., \& SANDERS, S. A. (1984). Prenatal gonadal steroid influences on gender-related behavior. In G. J. DeVries, J. P. C. DeBruin, H. B. M. Uylings, \& M. A. Corner (Eds.), Sex differences in the brain (Progress in Brain Research, Vol. 61, pp. 407-416). New York: Elsevier.
Sanders, G., \& Ross-Field, L. (1986a). Sexual orientation and visuospatial ability. Brain \& Cognition, 5, 280-290.

SANDERs G., \& Ross-Field, L. (1986b). Sexual orientation, cognitive abilities, and cerebral asymmetry: A review and a hypothesis tested. Italian Journal of Zoology, 20, 459-470.

SANDERS, G., \& Ross-FielD, L. (1987). Neuropsychological development of cognitive abilities: New research strategy and some preliminary evidence for a sexual orientation model. International Journal of Neuroscience, 36, 1-16.

Signorella, M. L., \& Jamison, W. (1986). Masculinity, femininity, androgyny and cognitive performance: A meta-analysis. Psychological Bulletin, 100, 207-228.

STORMs, M. D. (1981). A theory of erotic orientation development. Psychological Review, 88, 340-353.

VANDENBERG, S. G., \& KUSE, A. R. (1978). Mental rotations: A group test of three-dimensional spatial visualization. Perceptual \& Motor Skills, 47, 599-604.

WhITAM, F. L., \& MATHY, R. M. (1986). Male homosexuality in four societies: Brazil, Guatemala, The Phillipines, and the United States. New York: Praeger.

Wilmott, M., \& Brierley, R. (1984). Cognitive characteristics and homosexuality. Archives of Sexual Behavior, 13, 311-319.

\section{NOTE}

1. Typically, assessments of sexual orientation rely on subjects' selfreports during an interview or questionnaire (Ellis, Burke, \& Ames, 1987). A key assumption is made that a person reporting atypical sexual orientation (i.e., other than exclusive heterosexuality) is truthful and representative of that person's sexual history and is not underreported. In our laboratory, as in most sexuality programs, a reputation for strict procedures for confidential handling of data and interview records as well as professional behavior of staff members enhances compliance, cooperation, and openness of participants. Furthermore, it should be recalled that participants in this project are volunteers. Quite simply, individuals unwilling to discuss or disclose their sexual orientation do not participate in research of this type. Thus, although no method of interviewing can be perfectly reliable and valid in determining sexual orientation in persons desiring to conceal their erotic partner preferences, categorizing essentially self-reported sexual orientation in volunteers is relatively valid and reliable (for a review on this topic, see Coleman, 1987).

(Manuscript received September 8, 1989; revision accepted for publication December 1, 1989.) 